\title{
ONCOCYTIC SCHNEIDERIAN PAPILLOMA OF FRONTAL SINUS
}

\author{
David Kalfeřt ${ }^{1}$, Jan Laco ${ }^{2}$, Petr Čelakovský1, Katarína Smatanová1, Marie Ludvíkováa
}

Charles University in Prague, Faculty of Medicine in Hradec Králové, and University Hospital Hradec Králové, Czech Republic: Department of Otorhinolaryngology and Head and Neck Surgery ${ }^{1}$, The Fingerland Department of Pathology ${ }^{2}$; Charles University in Prague, Faculty of Medicine in Pilsen, Czech Republic: Institute of Biology ${ }^{3}$

Summary: Oncocytic Schneiderian papilloma (OSP) is one of the three morphologically distinct tumors that arise from Schneiderian membrane (the others include exophytic papilloma and inverted papilloma). OSP almost always occurs unilaterally in the paranasal sinuses, usually in the maxillary sinus, ethmoid cells or sphenoid sinus. We report a case of a 64-year-old woman with OSP arising from the left frontal sinus. In the report herein, we describe an OSP originating in the region of frontal sinus, which, to the best of our knowledge, represents the first documented example in English literature of OSP developing in this anatomical site.

Key words: Oncocytic Schneiderian papilloma; Frontal sinus; Headache; Surgical treatment

\section{Introduction}

Oncocytic Schneiderian papilloma (OSP), also known as cylindrical or columnar cell papilloma, is a rare sinonasal lesion that represents $3-19 \%$ of all three histological variants of sinonasal papillomas (the others include exophytic papilloma and inverted papilloma) (1-5). OSP is derived from Schneiderian membrane and composed of both exophytic fronds and endophytic invaginations lined by multiple layers of columnar cells with oncocytic features. Intraepithelial microcysts containing mucin and neutrophils (so-called microabscesses) are characteristic (2). OSP almost always occurs unilaterally in the paranasal sinuses, usually in the maxillary sinus, ethmoid cells or sphenoid sinus $(1,3)$. In the report herein, we describe an OSP originating in the region of frontal sinus, which, to the best of our knowledge, represents the first documented example in English literature of OSP developing in this anatomical site.

\section{Case report}

A 64-year-old woman presented with five years history of frontal headaches with sensation of pressure on the left side. She denied epistaxis, rhinorrhea or nasal obstruction. Physical examination, including nasal endoscopy, yielded normal findings. Previous ophthalmologic and neurological examinations were within normal findings. Computed tomography scan showed a mass in the left frontal sinus (Fig. 1 and 2). Differential diagnosis including chronic frontal sinusitis, frontal sinus cyst or mucosal thickening was considered. Indications for surgical treatment were relative, as frontal headache and pressure sensation on the left side of the forehead were the only symptoms and surgical removal of the lesion did not clearly guarantee the symptoms to disappear. The decision was therefore made after other causes of headache were excluded and a consultation with the patient who preferred surgical treatment. Patient underwent an endoscopic endonasal ethmoidectomy and frontal sinotomy with surgical removal of the cystic tumor. Location of the lesion (mass, tumor) in the medial part of the frontal sinus allowed us to consider to perform an endoscopic endonasal approach in contrast to lesions located in lateral part of the frontal sinus, where external approach is often preferred. Furthermore, primary endoscopic endonasal approach was preferred in view of the fact that the lesion was cystic (possibility of marsupialization) and malignancy was unlikely. However, the patient was informed about the possibility of conversion to an external surgical approach if required. Due to unclear diagnosis and due to fact that intraoperatively, the lesion did not appear as a simple retention cyst, biopsy of the lesion was performed and sent for histological examination. However, shaver was used to treat the sites of the tumor origin. Microscopic examination revealed oncocytic papilloma (Fig. 3 and 4). The patient is now without any complaints and remains in the care of our department.

\section{Discussion}

OSP is the rarest subtype of sinonasal papillomas, accounting for only $3 \%$ to $19 \%$ of all cases (1-5).

OSP occurs in patients from 26 to 83 years of age (4, $6-8)$. The majority of patients are over 50 years old. There is no sex or race predilection. We are describing a case of 64-years old woman. 


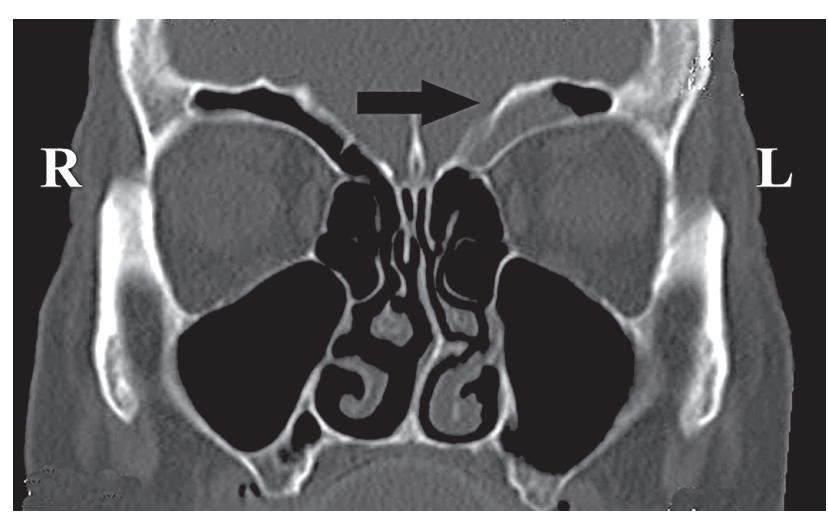

Fig. 1: Coronal computed tomography with bone window show partial opacification on the left frontal sinus (black arrow)

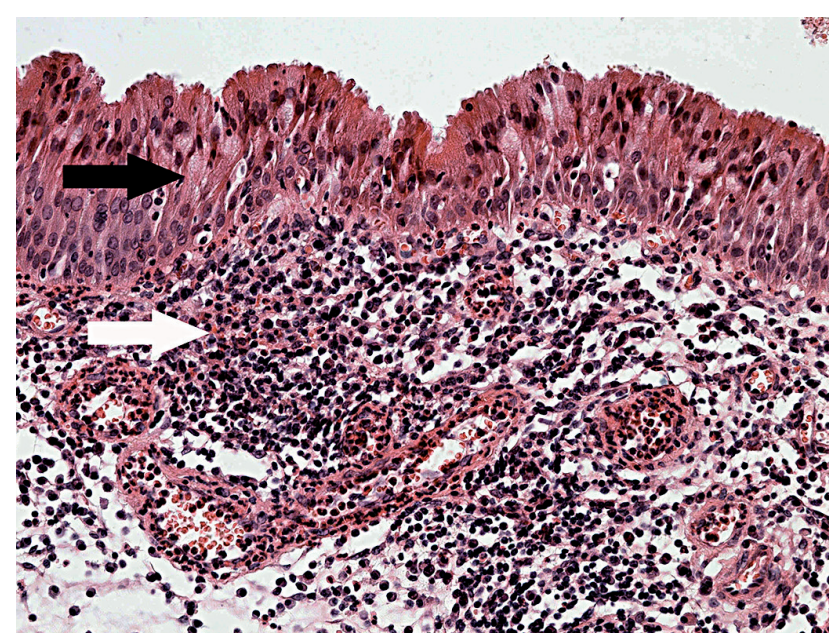

Fig. 3: The tumor is lined by multilayered columnar oncocytic epithelium (black arrow). Notice the presence on inflammatory cells within both stroma and epithelium (white arrow). (hematoxylin-eosin, original magnification $200 \times$ )

OSP almost always occurs unilaterally in the paranasal sinuses, usually in the maxillary sinus, ethmoid cells or sphenoid sinus. In contrast, inverted papilloma most commonly arise from the lateral wall of the nasal cavity with local extension to the paranasal sinuses $(1,3)$. A high incidence has OSP arising from or involving the maxillary sinus (3). All cases of OSP in both the series of Hyams (1) and the series of Barnes and Bedetti (2) involved the maxillary sinus. It may remain localized, or if neglected, extend into contiguous areas such as the orbit or cranial cavity (9). In our case OSP involved only left frontal sinus.

The clinical presentation of this disease is not well defined as only few cases have been published in the literature. The most common symptom of OSP is unilateral nasal

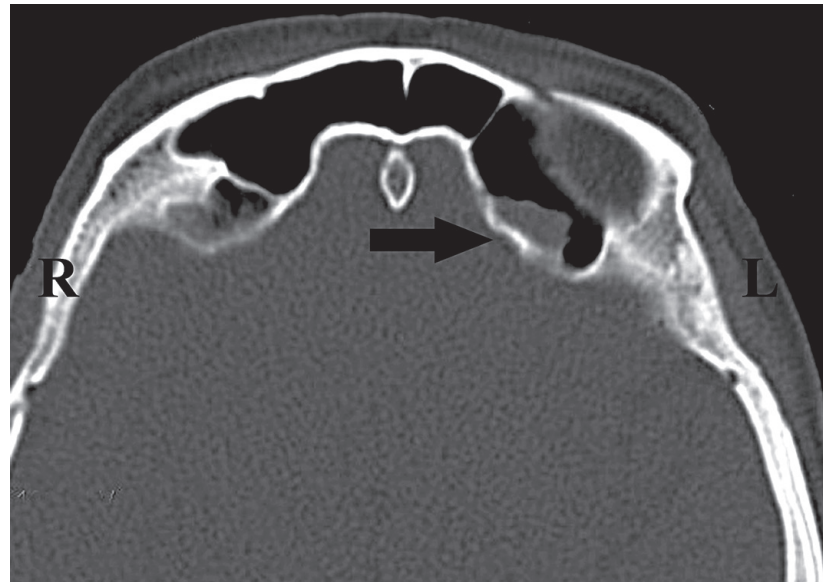

Fig. 2: Axial computed tomography with bone window show partial opacification on the left frontal sinus (black arrow)

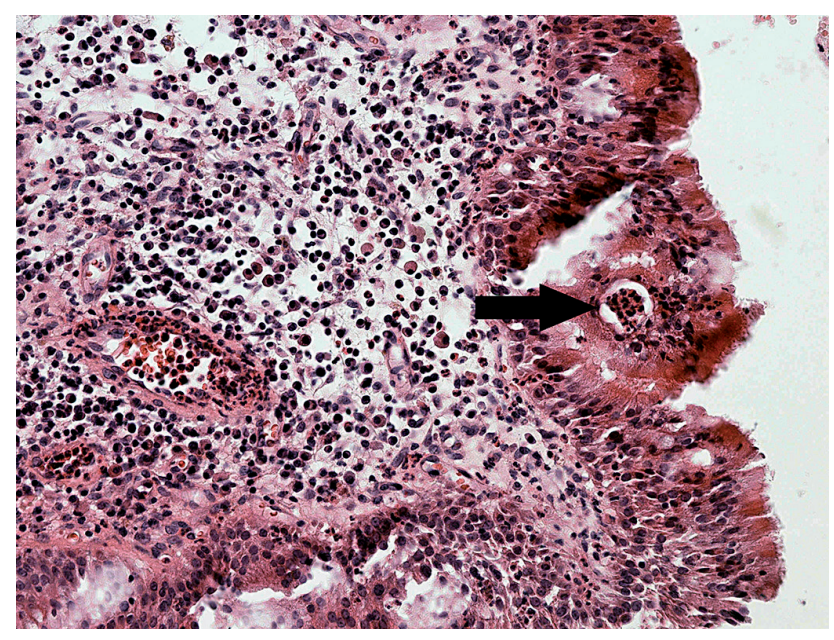

Fig. 4: The presence of intraepithelial microabscesses is characteristic (black arrow). (hematoxylin-eosin, original magnification $200 \times)$

obstruction. OSP presents as a fleshy, pink, reddish-brown or grey, papillary or polypoid mass. Intermittent unilateral epistaxis, headache, nasal discharge or proptosis may also accompany nasal obstruction (4). The duration of these symptoms usually ranges from months to years. All cases known to date have been unilateral $(1,4)$. Patient in our case suffered from pain with sensation of pressure on left forehead denying any other symptoms.

Imagings (radiography or computed tomography CT) show changes within the ipsilateral nasal sinus. The most common finding is an opacification associated with low-density intranasal tissue (3). Bone destruction suggests concomitant malignancy. In case of intracranial invasion, magnetic resonance imaging study is necessary in order to evaluate features of the neoplastic process (9). 
OSP exhibits both exophytic and endophytic growth patterns. The epithelium is multilayered, 2-8 cells thick, and is composed of tall columnar cells with swollen, finely granular cytoplasm reminiscent of oncocytes. The high content of cytochrome c oxidase and presence of numerous mitochondria ultrastructurally clearly establish their oncocytic character. The nuclei are either dark small and uniform or slightly vesicular with barely discernible nucleoli. Cilia in varying stages of regression may be observed in few of the outermost cells. The epithelium characteristically contains numerous small cysts filled with mucin or neutrophils (so-called microabscesses). The stroma varies from edematous to fibrous, and may contain modest number of lymphocytes, plasma cells, neutrophils and scattered eosinophils. Seromucinous glands are sparse to absent (2).

The recurrence rate of OSP is about 33-40\% (compared to $12-39 \%$ of inverted papilloma) $(1,3,10)$. Malignancy arising from OSPs is very rare, with invasive squamous cell carcinoma being the most frequently reported tumor (11). Kaufman et al. assessed 9 cases of OSP and found a $17 \%$ rate of malignant transformation as compared with $9 \%$, respectively, for 34 cases of inverted papilloma (3).

Surgical treatment (endoscopic endonasal or external approach) depends on the size and mainly localization of tumor. Nowadays many authors prefer an endoscopic endonasal approach as useful, safe and minimally invasive technique. In the hand of experienced and skilled surgeon, complete endoscopic removal is attainable in most cases. However, several authors prefer an external approach for complete removal of the tumor, which is also indicated in cases where tumor is located in areas difficult to reach by endoscopic approach $(3,9,12,13)$.

\section{Conclusion}

OSP is a rare sinonasal lesion. OSP almost always occurs unilaterally in the paranasal sinuses, usually in the maxillary sinus, ethmoid cells or sphenoid sinus, but also in the frontal sinus. When OSP occurs only in the frontal sinus, patient could suffer only from frontal headache. If physical examination is with normal findings, CT of paranasal sinuses must be indicated. Surgical treatment depends on size and localization of the tumor. The tumor can be successfully treated by endoscopic approach, if it isn't located in the lateral part of the frontal sinus. Due to the possible recurrence of OSP and the eventual development into a malignant tumor, a regular and consistent follow-up is important.

\section{Acknowledgements}

This study was supported by the research project of Charles University Grant Agency (Grant No. 444311), by programme PRVOUK P37/11, project LM2010004 and by the Charles University Research Fund (project number P36).

\section{References}

1. Hyams VJ. Papillomas of the nasal cavity and paranasal sinuses. A clinicopathological study of 315 cases. Ann Otol Rhinol Laryngol 1971; 80: 192-206.

2. Barnes L, Bedetti C. Oncocytic Schneiderian papilloma: a reappraisal of cylindrical cell papilloma of the sinonasal tract. Hum Pathol 1984; 15: 344-351.

3. Kaufman MR, Brandwein MS, Lawson W. Sinonasal papillomas: clinicopathologic review of 40 patients with inverted and oncocytic Schneiderian papillomas. Laryngoscope 2002; 112: 1372-1377.

4. Kapadia SB, Barnes L, Pelzman K, et al. Carcinoma ex oncocytic Schneiderian (cylindrical cell) papilloma. Am J Otolaryng 1993; 14: 332-338.

5. Michaels L. Benign mucosal tumors of the nose and paranasal sinuses. Semin Diagn Pathol 1996; 13: 113-117.

6. Cunningham MJ, Brantley S, Barnes L, Schramm VL, Jr. Oncocytic Schneiderian papilloma in a young adult: a rare diagnosis. Otolaryngol Head Neck Surg 1987; 97: $47-51$

7. Olusina D, Nzegwu MA, Okoroafor IJ. Oncocytic Schneiderian papilloma occurring in a young Nigerian male: a case report. Ann Afr Med 2008; 7: 91-93.

8. Cheng TY, Ueng SH, Chen YL, Chang KP, Chen TM. Oncocytic Schneiderian papilloma found in a recurrent chronic paranasal sinusitis. Chang Gung Med J 2006; 29: 336-341

9. Bignami M, Pistochini A, Meloni F, Delehaye E, Castelnuovo P. A rare case of oncocytic Schneiderian papilloma with intradural and intraorbital extension with notes of operative techniques. Rhinology 2009; 47: 316-319.

10. Sautter NB, Cannady SB. Comparison of open versus endoscopic resection of inverted papilloma. Am J Rhinol 2007; 21: 320-323.

11. Maitra A, Baskin LB, Lee EL. Malignancies arising in oncocytic Schneiderian papillomas: a report of 2 cases and review of the literature. Arch Pathol Lab Med 2001; 125: 1365-1367.

12. Wormald PJ, Chan SZ. Surgical techniques for the removal of frontal recess cells obstructing the frontal ostium. Am J Rhinol 2003; 17: 221-226.

13. Balatková Z, Vokurka J, Plzák J, Betka J. Léčba invertovaného papilomu. Endoskopie 2012; 21: 34-36.

\section{Corresponding author:}

Accepted in revised form: 10/11/2013

David Kalfeřt, Department of Otorhinolaryngology and Head and Neck Surgery, University Hospital Hradec Králové, Sokolská 581, Hradec Králové 500 05, Czech Republic; e-mail: kalfertd@lfhk.cuni.cz 